\title{
Effect of Sand Fouling on the Dynamic Properties and Volume Change of Gravel During Cyclic Loadings
}

\author{
Meysam Bayat ${ }^{1 *}$ \\ ${ }^{1}$ Department of Civil Engineering, Najafabad Branch, Islamic Azad University, 8514143131, Najafabad, Iran \\ * Corresponding author, e-mail: bayat.m@pci.iaun.ac.ir
}

Received: 03 March 2020, Accepted: 18 April 2020, Published online: 28 May 2020

\begin{abstract}
Understanding the factors that influence the dynamic behavior of granular soils during cyclic loading is critical to infrastructure design. Previous research has lacked quantitative study of the effects of fouling index (FI), mean effective confining pressure, relative density, shear strain level and anisotropic consolidation, especially when the effective vertical stress is lower than the effective horizontal stress on the dynamic behavior of gravelly soils. The objective of the present study was to evaluate the dynamic behavior and volume change of both clean and fouled specimens for practical applications. To this end, cyclic triaxial tests with local strain measurements under both isotropic and anisotropic confining conditions were conducted. It is found that the fouled specimen with $50 \%$ sand (i.e. the specimen which contains $50 \%$ gravel and $50 \%$ sand) has the highest shear modulus at low shear strain levels and the largest volume reduction and damping ratio at large shear strain levels. The results of tests indicate that the effect of fouling index on the shear modulus is reduced at large shear strain levels. Volumetric contraction due to the increase in mean effective confining pressure is more significant at large shear strain levels. The results also indicate that the stiffness of the specimens under anisotropic compression mode are larger than those in extension or isotropic mode.
\end{abstract}

\section{Keywords}

gravel, stiffness, damping ratio, volume change, sand

\section{Introduction}

Vibrations ground are a matter of growing concern, especially in densely populated cities and states. Beside natural vibration sources as seismic and wave loading, as well as artificial sources generating vibrations gained in importance in recent years as recent developments lead to a significant increase of the traffic volume. As a result, significant higher vibration amplitudes as in the past are observed which can result in increased dynamic loading and may lead to a reduction of durability and service lifetime of civil structures, such as bridges, road embankment, buildings, tunnels and dams [1]. For this reason, it is useful understanding of the soil mechanisms during vibration loading with respect to their damage risks for civil structures.

Dynamic loading of embankment, rail transport, foundation and pavement structures results in particle breakage and variations in microstructure of the granular materials, when the stresses imposed on the granular particles exceed their strength. Particle breakage is dependent on a number of 'macro-scale' parameters and characteristics of the constituent particles such as the grain size distribution, grain shape and size, particle roughness, initial void ratio, magnitude of stress, and mineralogy. Particle crushing affects the dilatancy behavior, compressibility, mechanical and hydraulic characteristics of granular material [2-4].

The mechanical and dynamical behavior of granular soils generally consist of boulders, cobbles and coarse gravel is governed by properties of the constituting particles, bulk properties of the granular medium, loading characteristics and particle degradation. Slip, sliding, rotation and rolling are four micro-mechanical processes that affect the global deformation of the granular medium under cyclic loading which can be result in an increase in settlement. When the voids of the gravel are wholly or partially filled by fines, the soil is considered to be fouled which results in decreasing bearing capacity and consequently increasing the plastic deformation [5-7]. By increasing the fines content, fine particles can govern the mechanical behavior of 
medium and ultimately decreases performance, void ratio, drainage capacity, resulting in higher settlement, and localized undrained failure [8-13]. Sources of fouling consist of particle breakage, clay pumping, infiltration of underlying and foreign materials. In order to quantify the degree of fouling, Selig and Waters [14] have defined the Fouling Index (FI), which defined as Eq. (1):

$$
F I=P_{4}+P_{200},
$$

where $P_{4}$ and $P_{200}$ are percentage (by weight) passing $4.75 \mathrm{~mm}$ and $0.075 \mathrm{~mm}$ sieves, respectively. The fouling of gravel materials was reproduced in laboratory through mixing the clean gravel material with fine soil (fine sand, clays, and silt-size particles). Huang et al. [15] conducted large direct shear tests on ballast material to evaluate the effect of fouling material on ballast shear strength. The results indicated that the shear strength decreased steadily with an increase in the fouling content, which is in a good agreement with the results reported by Danesh et al. [16, 17]. Qian el al. [18] carried out a series of large triaxial to evaluate plastic deformation of both clean and degraded gravel specimens. Results indicated that plastic deformation of degraded gravel specimens is approximately three times higher than clean gravel specimens. Particle breakage is commonly observed in coarse granular soils including ballast and rockfill materials when subjected to static or dynamic loads which is affected by the mean effective confining pressure, strain level and stress path [19-21]. It is a critical issue for granular aggregates which have received a great attention in the literature [22-27]. Previous studies indicated that particle breakage directly modifies the rockfill structure, influencing its dilatancy, shear strength parameter, and permeability, as well as generating plastic deformation under a seismic load [10, 21, 28-32]. Yu [33] carried out a series of triaxial tests to study the particle breakage. The results indicate that soil particle breakage results in a reduction of the strength of granular materials and induce more plastic deformation. Lenart et al. [34] performed a series of largescale triaxial tests on reconstituted gravel specimens. Deformations of the specimens were measured locally by using local displacement transducers. They reported that the tangent modulus $\left(E_{t a n}\right)$ increased noticeably for all deviator stress levels smaller than the one used during preloading and increased noticeably due to increase of the deviator stress. Andrianatrehina et al. [34] studied the influence of the fine content on the undrained mechanical behavior of a granular soil using Consolidated undrained triaxial tests. The results indicated that increase of fine content reduces undrained strength and the dilative phase amplitude. Goudarzy et al. [35] investigated the small strain moduli ( $G_{\max }, M_{\max }$ and $\left.E_{\max }\right)$ of the granular materials containing fines using resonant column and compression wave velocity Testing Techniques. They conducted that the small strain moduli of the coarse granular materials are significantly affected by the fines content which is dependent on the particle characteristics, fine content, and position of the fine particles in the coarse matrix. Some of the research used intergranular void ratio as an alternative parameter to assess the mechanical and dynamic behavior of composite matrix of coarse and fine grains [36-38].

Even though, many studies have been done to investigate the effect of fouling sand or fine content on mechanical behavior of gravel materials, there are no studies on the effect of fouling sand on dynamic properties and volume change of gravel specimens. The objective of the present study is to investigate the dynamic properties and volume change of both clean and sand-fouled gravel specimens at various levels of fouling under cyclic loadings. It summarizes the findings from an experimental program assessing the dynamic properties and volume change of both clean and sand-fouled gravel specimens were tested at different relative densities, men effective confining pressures and initial deviatoric stresses.

\section{Materials, testing programs and specimen preparation}

Fig. 1 illustrates the particle size distribution curves of both clean gravel and the fouling sand used in the present study. According to the unified soil classification, the fouling sand and gravel are categorized as poorly graded sand $(S P)$ and poorly graded gravel $(G P)$, respectively.

The physical properties of the gravel and sand are provided in Table 1. Table 2 summarizes the cyclic triaxial tests performed in the present study. Maximum and minimum

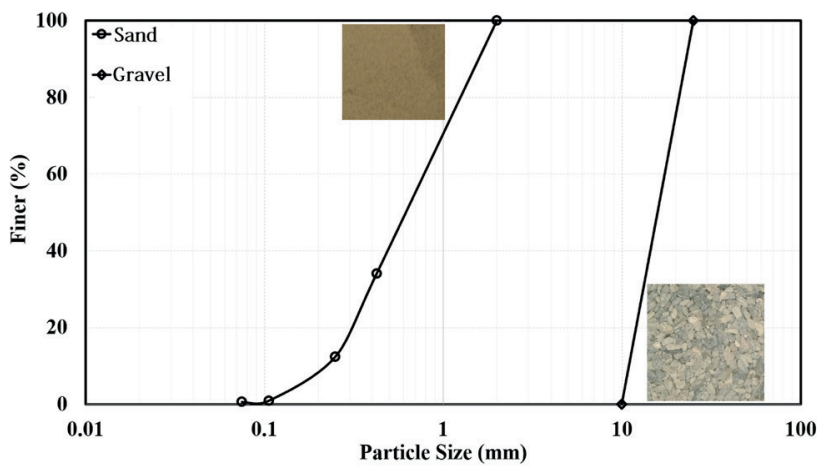

Fig. 1 Gradations of gravel and fouling sand 
Table 1 Physical properties of the sand and gravel

\begin{tabular}{lcc}
\hline Parameter & Sand & Gravel \\
\hline$G_{s}$ & 2.645 & 2.684 \\
$D_{\text {min }}(\mathrm{mm})$ & 0.075 & 10 \\
$D_{\text {max }}(\mathrm{mm})$ & 2 & 25 \\
$e_{\text {min }}$ & 0.658 & 0.665 \\
$e_{\text {max }}$ & 0.91 & 0.847 \\
$\gamma d_{- \text {min }}\left(\mathrm{kN} / \mathrm{m}^{3}\right)$ & 13.56 & 14.29 \\
$\gamma d_{-\max }\left(\mathrm{kN} / \mathrm{m}^{3}\right)$ & 15.63 & 15.83 \\
\hline
\end{tabular}

Table 2 Summary of the tests details

\begin{tabular}{|c|c|c|c|c|}
\hline $\begin{array}{c}\text { Effective confining } \\
\text { stress }(\mathrm{kPa})\end{array}$ & $F I(\%)$ & $D_{r 0}(\%)$ & $K=\frac{\sigma_{c l}^{\prime}}{\sigma_{c a}^{\prime}}$ & $\begin{array}{l}\text { No. of cyclic } \\
\text { triaxial tests }\end{array}$ \\
\hline \multirow{5}{*}{600} & 0 & & \multirow{5}{*}{1} & \multirow{5}{*}{15} \\
\hline & 30 & 10 & & \\
\hline & 50 & 30 & & \\
\hline & 75 & 60 & & \\
\hline & 100 & & & \\
\hline \multirow{3}{*}{$\begin{array}{l}100 \\
300 \\
600\end{array}$} & \multirow[t]{2}{*}{0} & & & \multirow{3}{*}{6} \\
\hline & & 60 & & \\
\hline & 100 & & & \\
\hline \multirow{5}{*}{300} & \multirow{3}{*}{0} & & 0.5 & \multirow{5}{*}{10} \\
\hline & & & 0.75 & \\
\hline & & 60 & 1 & \\
\hline & \multirow[t]{2}{*}{100} & & 1.25 & \\
\hline & & & 1.5 & \\
\hline
\end{tabular}

void ratios $\left(e_{\max }\right.$ and $\left.e_{\min }\right)$ represent the loosest and densest conditions based on fouling sand content are presented in Fig. 2. The minimum and maximum void ratios were obtained for the soils according to ASTM-D4253 and D4254, respectively.

In the previous studies, the stiffness and damping ratio of soils were evaluated on the basis of varied laboratory techniques, namely, cyclic triaxial test, resonant column or bender element tests (e.g. [39, 40, 49, 41-48]).

In the present study, as shown in Fig. 3(a), a cyclic triaxial apparatus was used to measure the stiffness degradation and volume change of the specimens for a wide range of shear strain amplitudes.

Cyclic triaxial tests were conducted on the cylindrical soil specimens, which were prepared using moist-tamping method with a low initial water content. The moist-tamping method produces very loose to dense granular soil specimens which has the advantage of easy control of soil density and porosity [50-52]. The sand and gravel mixture with a low initial water content about $3 \%$ was compacted after mixing into the split mold in six layers of

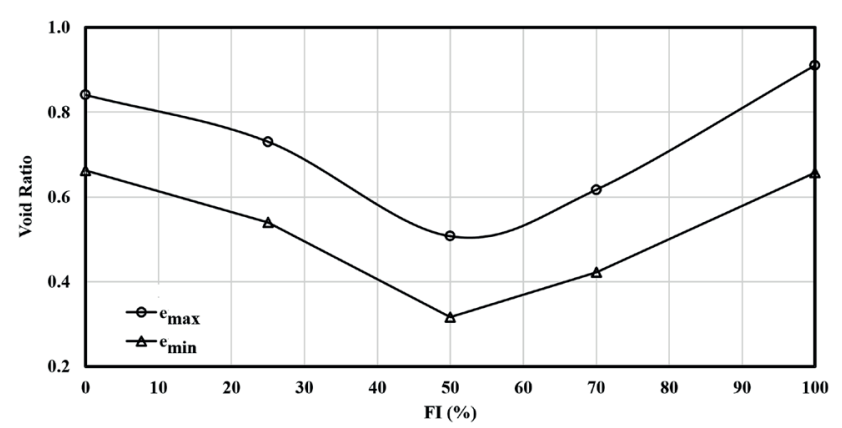

Fig. 2 Maximum and minimum composite void ratios versus fouling index

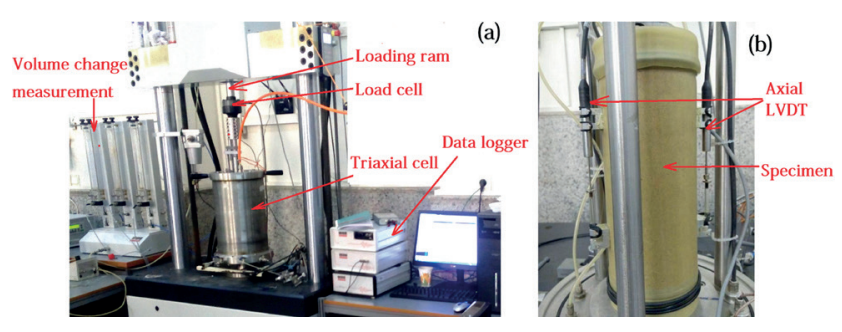

Fig. 3 (a) Cyclic triaxial apparatus used in the experimental program; (b) Prepared specimen along with two LVDT's

equal height and each layer was compacted a metal hammer with a graduated vertical rod to control the desired height by abutting against the edges of the mold. In order to achieve a uniform specimen, the specimens were compacted using the under-compaction technique proposed by Ladd [53]. The number of blows were varied to prepare homogeneous specimens. Karim and Alam [54] indicated that in moist-tamping method, homogenous soil structure is developed. As maintained before, initially low water content was mixed with dry soil in the moist-tamping method. As a result, the cohesive forces or surface tension forces develop in the sand and gravel particles, which are shared with all neighboring particles in the specimen and, as a consequence a homogeneous fabric is developed after tamping. After specimen preparation, dimension measurement and instrument installation, full saturation is required to measure volume change continuously during test procedure. For this purpose, $\mathrm{CO}_{2}$ was passed through the specimen followed by de-aired water. The specimen was saturated according to ASTM-D5311 by applying cell pressure and sufficient back pressure. This stage was terminated when the Skempton's B-parameter was equal to or higher than 0.95 [55]. Following the saturation process, the soil specimens were consolidated under desired condition (anisotropic or isotropic consolidation) and then subjected to cyclic loading. For example, three kinds of loading paths under isotropic and anisotropic consolidations are shown in Fig. 4. A-B path indicates the applied low 
effective confining stress of about $20 \mathrm{kPa}$ before the saturation stage. $\mathrm{B}-\mathrm{C}$ path indicates the applied effective confining stress of $300 \mathrm{kPa}$ during the isotopic consolidation path. $\mathrm{C}-\mathrm{D}$ path indicates the applied negative deviatoric stress for the specimen which consolidated under anisotropic consolidation (effective confining pressure equal to $300 \mathrm{kPa}$ and $K_{C}=1.5$ ). C-E path indicates the applied positive deviatoric stress for the specimen which consolidated under anisotropic consolidation (effective confining pressure equal to $300 \mathrm{kPa}$ and $K_{C}=0.5$ ). Drainage was allowed during in all these stages.

The cyclic triaxial tests were carried out according to the procedure defined by ASTM-D3999. As shown in Fig. 5(a), each stage of loading consisted of 40 loading cycles, began with small constant cyclic shear stress loading, and gradually increased as the shear stress amplitudes increased. The cyclic loading was applied with a constant

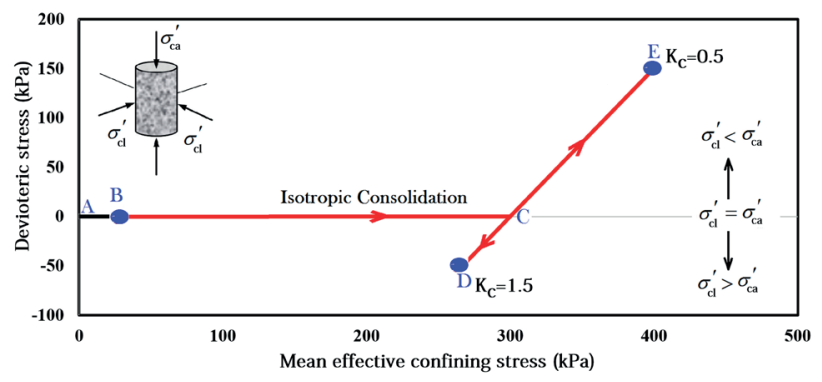

Fig. 4 examples for the anisotropic and isotropic consolidations stress paths
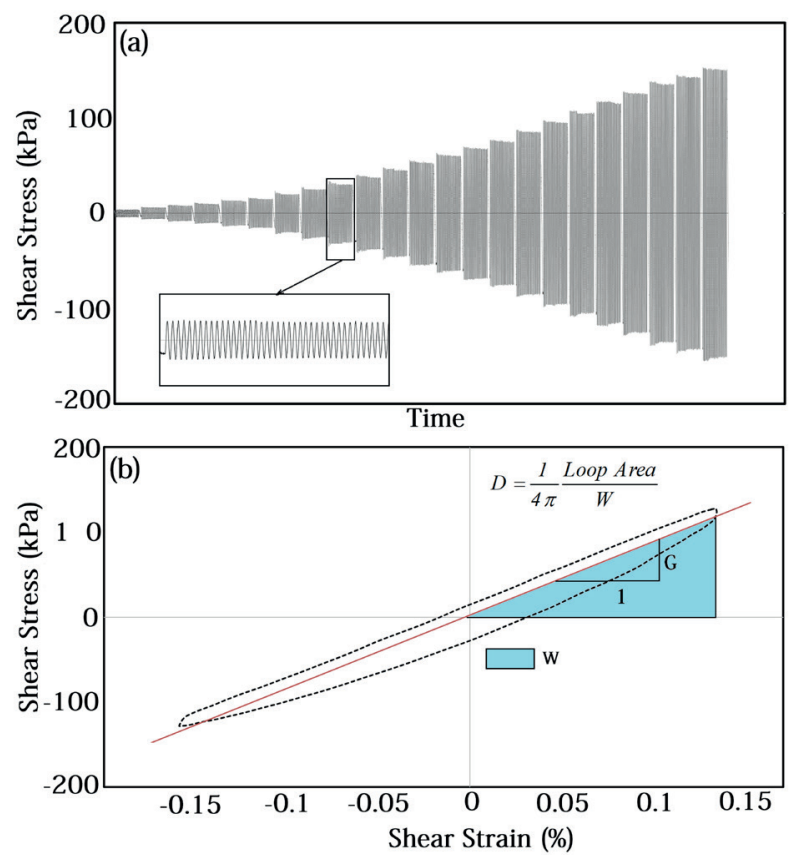

Fig. 5 (a) Recorded multi-cyclic loading; (b) Hysteresis loop showing secant shear modulus and damping ratio frequency of $1 \mathrm{~Hz}$ and a sinusoidal waveform in all loading stages. Drainage was not allowed during each stage of loading, and the accumulated excess pore water pressure at the end of loading stage was released by opening the drainage valves before the next stage of loading. The volume changes of the specimen were measured at the end of each loading stage by the volume of water exchanged along the drainage line. As shown in Fig. 3(b), axial strain was recorded from the two LVDT's that were installed directly on both sides of the specimen. The shear modulus value can be computed on each of the hysteresis loop at 1 to 5 , 10, 20, and 40 cycles as recommended in ASTM-D3999. In the present study, shear modulus and damping ratio was computed from the hysteresis loop of the tenth load cycle (See Fig. 5(b)).

\section{Results and discussions}

The stiffness, damping ratio and volume change of the specimens have been studied by cyclic triaxial tests. The effects of fouling content, relative density, mean effective confining pressure and initial deviatoric stress (anisotropic consolidation) on the stiffness, damping ratio and volume change are particularly examined. Figs. 6 to 8 present the shear modulus, damping ratio, and relative density versus shear strain levels under mean effective confining pressure of $600 \mathrm{kPa}$, different initial relative densities and fouling contents. The specimens are named based on their fouling index. As shown in the figures, the shear modulus, damping ratio, and relative density are highly sensitive to shear strain amplitude. Clearly, shear modulus and relative density or damping ratio are monotonically decreasing and increasing with the shear strain amplitude increasing, respectively. The results also indicate that the stiffness degradation rate is dependent on the fouling index especially at low shear strain levels. However, the variation in damping ratio with a changes in the fouling index is more impressive at large shear strain levels. The fouled gravel with $50 \%$ sand has the higher shear modulus at low shear strain levels and has the higher damping ratio than other specimens for a given relative density. It is noteworthy that, the values of void ratio decrease with an increase in gravel content from $0 \%$ to $50 \%$. The gravel specimens containing $50 \%$ sand had the lowest void ratio when compared with the other specimens at a given relative density. The point to point contacts between the particles increases and the soil particles were close to each other. The highest damping ratio in the gravel specimens containing $50 \%$ sand show that the part of the sand particles in contact with the surface of the 

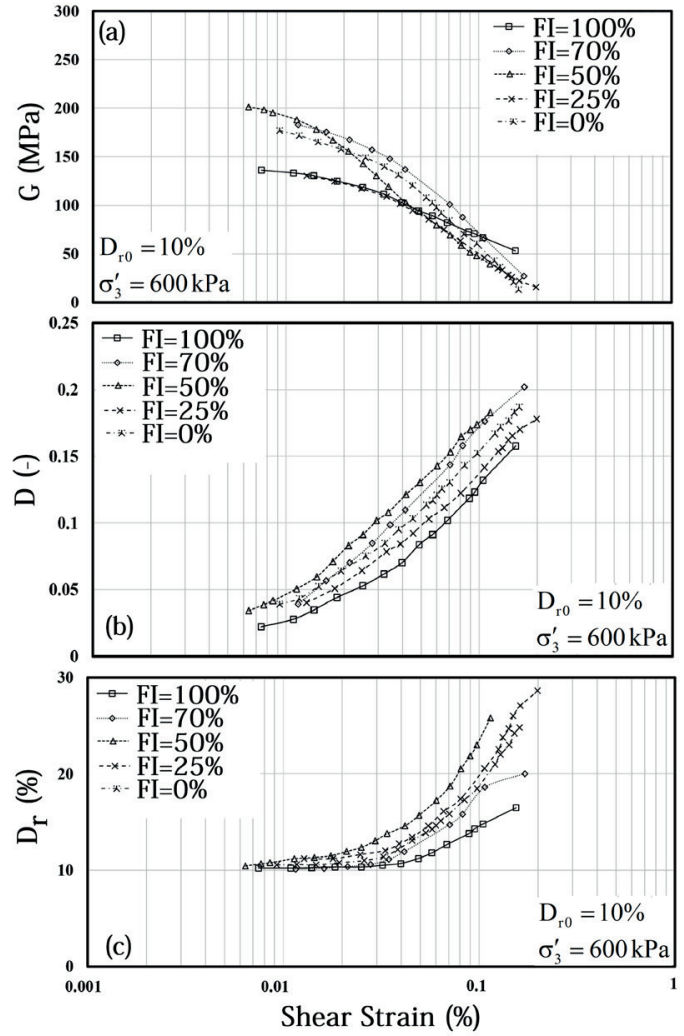

Fig. 6 (a) Variation of $G$; (b) Variation of $D$; (C) variation of $D_{r}$ as a function of $\gamma$ in terms of fouling index $\left(D_{r 0}=10 \%\right.$ and $\left.\sigma_{3}^{\prime}=600 \mathrm{kPa}\right)$
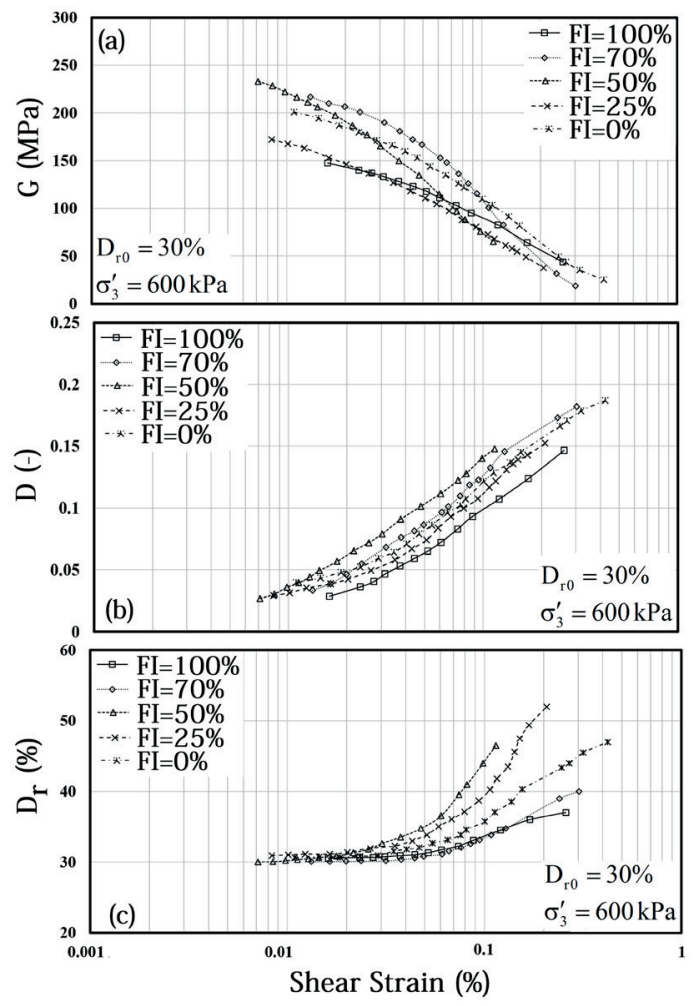

Fig. 7 (a) Variation of $G$; (b) Variation of $D$; (C) variation of $D_{r}$ as a function of $\gamma$ in terms of fouling index $\left(D_{r 0}=30 \%\right.$ and $\left.\sigma_{3}^{\prime}=600 \mathrm{kPa}\right)$
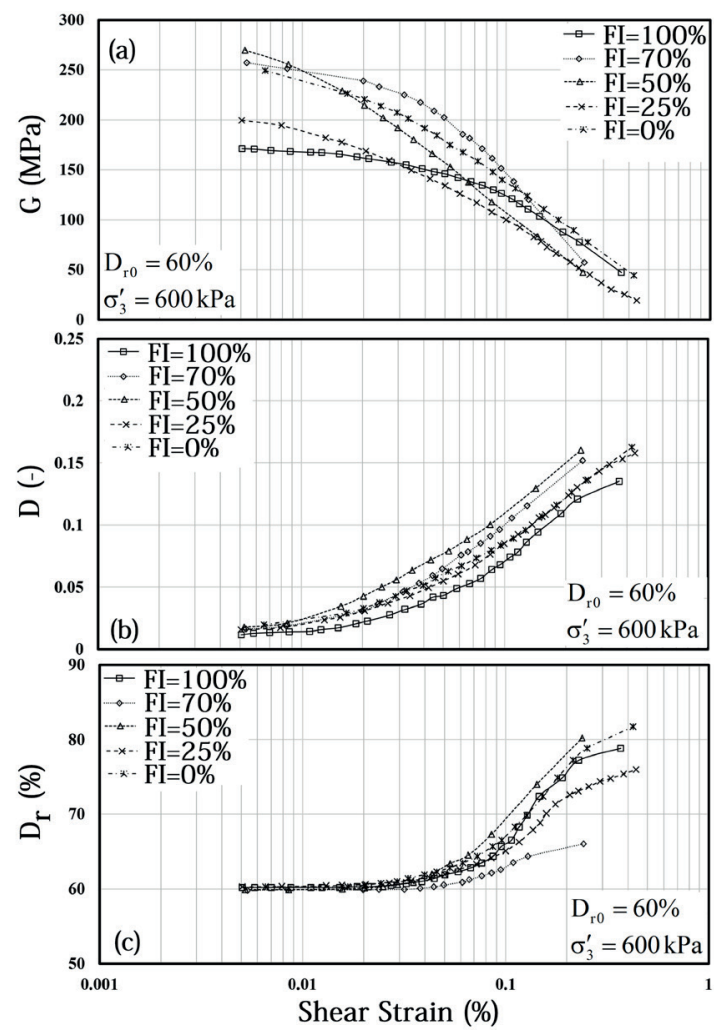

Fig. 8 (a) Variation of $G$; (b) Variation of $D$; (C) variation of $D$ as a function of $\gamma$ in terms of fouling index $\left(D_{r 0}=60 \%\right.$ and $\left.\sigma_{3}{ }^{\prime}=600 \mathrm{kPa}\right)$

gravel particles caused separation and sliding of the gravel particles under cyclic loading. In general, the stiffness degradation more quickly as the GC increased up to a threshold value (sand content $=50 \%$ ), at which point the sand particles were close to each other and the gravel particles broke away. However, the variation in shear modulus with a change in fouling index is not more impressive at large shear strain levels.

The results also indicate that the fouled gravel specimens which contained $50 \%$ sand have higher compressibility and recovery under cyclic loading than other specimens when deformed to the same strain level at a given relative density, whereas the clean gravel specimens exhibit the lowest volumetric contraction under cyclic loading. This finding is in good agreement with the observation of Esmaeili et al. [52].

In the clean gravel material, coarse gravel particles are in contact with each other and the behavior of the specimens under cyclic loading are controlled by the gravel particles. When the contacts between the gravel particles reduce, the behavior of the specimens becomes to sandgravel mixture like. In this condition, a part of fouled gravel specimens that is placed in contact surfaces of gravel particles leads to separation and sliding the gravel 
particles during cyclic loading which leads to the increase of soil compressibility and the decrease of soil stiffness at large shear strain levels. These findings are consistent with experimental results reported by previous studies $[38,56]$. The results also confirm that the shear modulus and damping ratio is dependent of relative density for a given value of the shear strain amplitude and fouling index.

The shear modulus and damping ratio of the specimens slightly increased and decreased with an increase in initial relative density, which is similar to previous reports for granular materials [57, 58].

Figs. 9 and 10 indicate the shear modulus, damping ratio, and relative density versus shear strain for both clean gravel and fouling sand under various effective confining pressures $(100,300$ and $600 \mathrm{kPa})$, respectively. As shown in the results, effective confining pressure has an important effect on the dynamic properties and volume change of both clean gravel and fouling sand. As expected, shear modulus or volumetric contraction and damping ratio increased and decreased as the effective confining pressure increased, respectively. The effect of the effective confining pressure on the volume change of both clean gravel and fouling sand under cyclic loading at small and medium shear strain levels is not very important, whereas this effect is more pronounced for shear strains greater than $0.02 \%$.

Figs. 11 and 12 indicate the shear modulus, damping ratio, and ratio of relative density to initial relative density $\left(D_{r} / D_{r 0}\right)$ versus shear strain for both clean gravel and fouling sand with different initial relative densities $(10 \%, 30 \%$ and $60 \%$ ), respectively. As shown in the figures, initial relative density has an important effect on the dynamic properties of both clean gravel and fouling sand. As expected, shear modulus and damping ratio increased and decreased as the initial relative density increased, respectively. The effect of the initial relative density on the $D_{r} / D_{r 0}$ of both clean gravel and fouling sand under cyclic loading at small and medium shear strain levels is not important, whereas this effect is more pronounced for shear strains greater than $0.03 \%$. The specimens with lowest relative density (i.e. $D_{r 0}=10 \%$ ) experienced the greatest change of $D_{r} / D_{r 0}$.

The effect of anisotropic consolidation on dynamic properties and relative density versus shear strain for both clean gravel and fouling sand under constant effective confining pressure $(300 \mathrm{kPa})$ is presented in Figs. 13 and 14, respectively. In the present study, initial consolidation stress ratio $\left(K_{C}=\sigma_{h} / \sigma_{v}\right)$ used to describe induced anisotropy, where $\sigma_{h}$ and $\sigma_{v}$ are horizontal and axial effective consolidation stress, respectively.

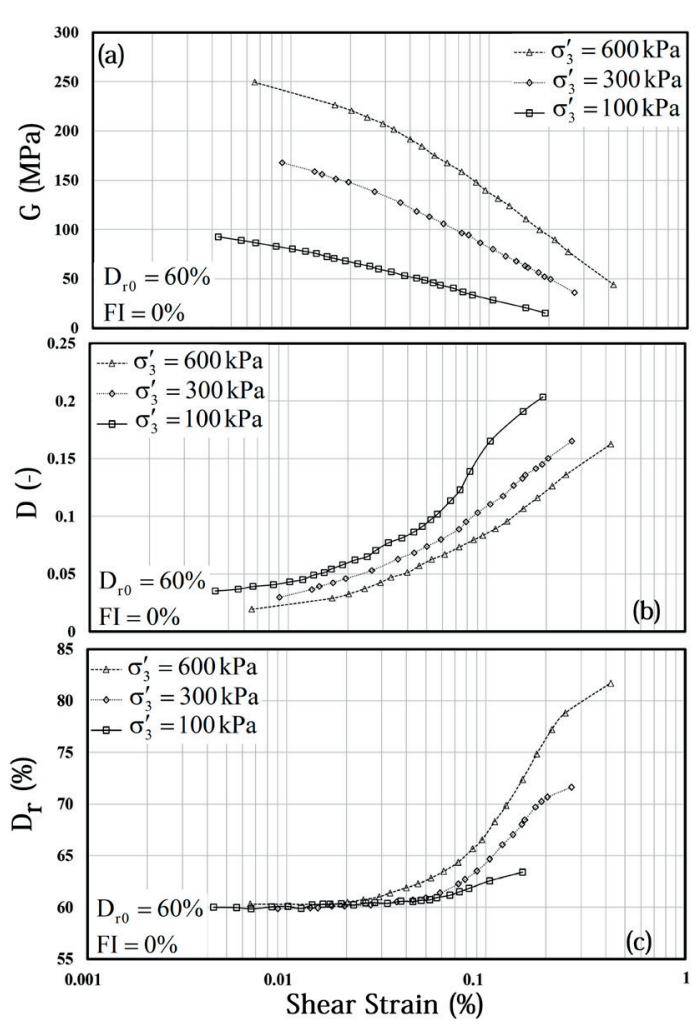

Fig. 9 (a) Variation of $G$; (b) Variation of $D$; (C) variation of $D_{r}$ as a function of $\gamma$ in terms of mean effective confining pressure $\left(D_{r 0}=60 \%\right.$ and $F I=0 \%)$
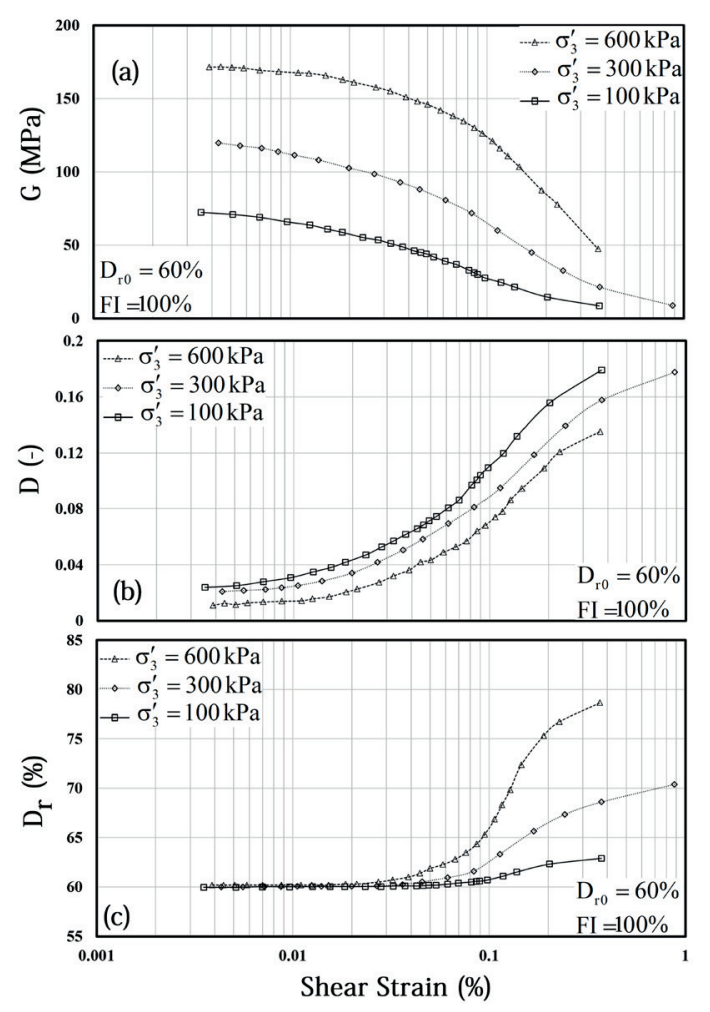

Fig. 10 (a) Variation of $G$; (b) Variation of $D$; (C) variation of $D_{r}$ as a function of $\gamma$ in terms of mean effective confining pressure $\left(D_{r 0}=60 \%\right.$ and $F I=100 \%$ ) 

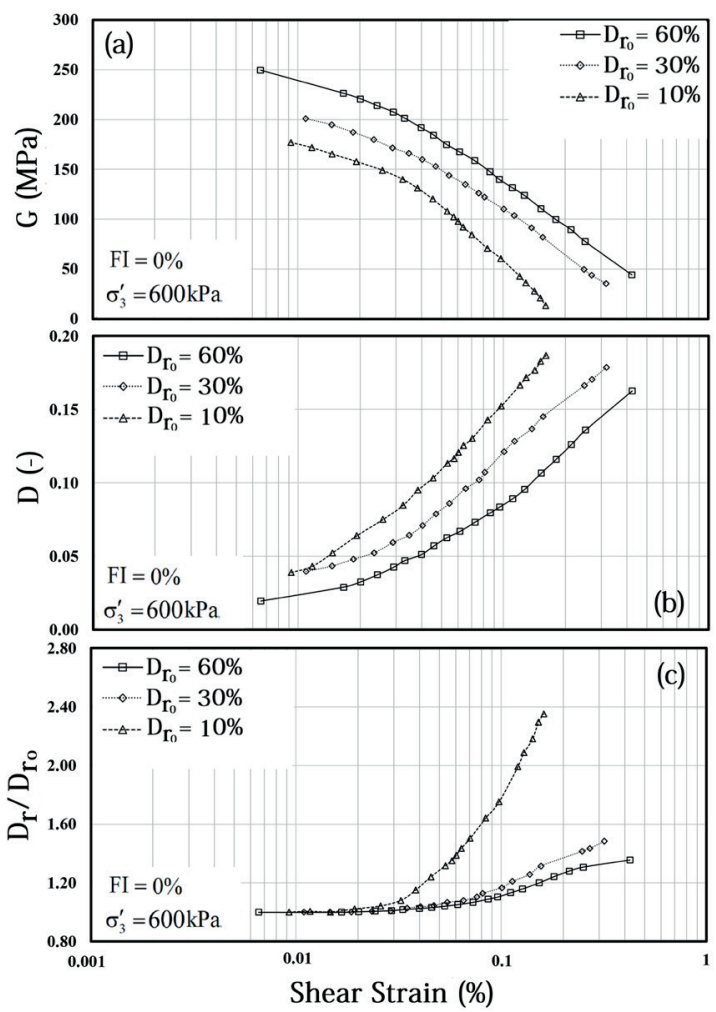

Fig. 11 (a) Variation of $G$; (b) Variation of $D$; (C) variation of $D_{r} / D_{r 0}$ as a function of $\gamma$ in terms of relative density $\left(F I=0 \%\right.$ and $\left.\sigma_{3}^{\prime}=600 \mathrm{kPa}\right)$
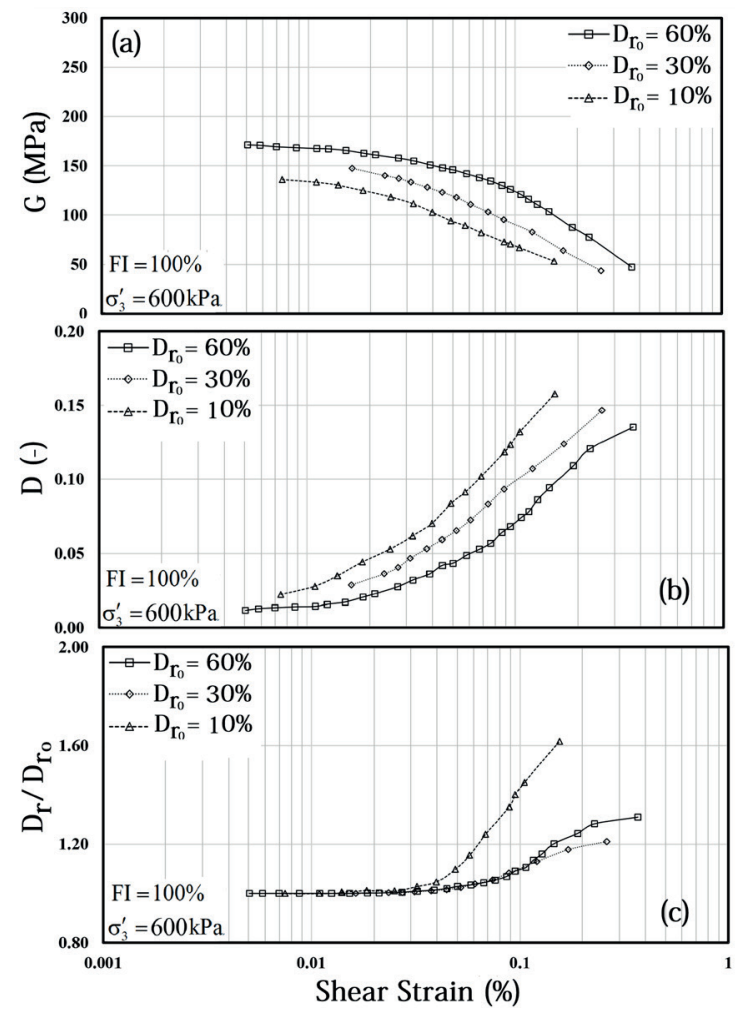

Fig. 12 (a) Variation of $G$; (b) Variation of $D$; (C) variation of $D_{r} / D_{r 0}$ as a function of $\gamma$ in terms of mean effective confining pressure $\left(F I=100 \%\right.$ and $\left.\sigma_{3}^{\prime}=600 \mathrm{kPa}\right)$
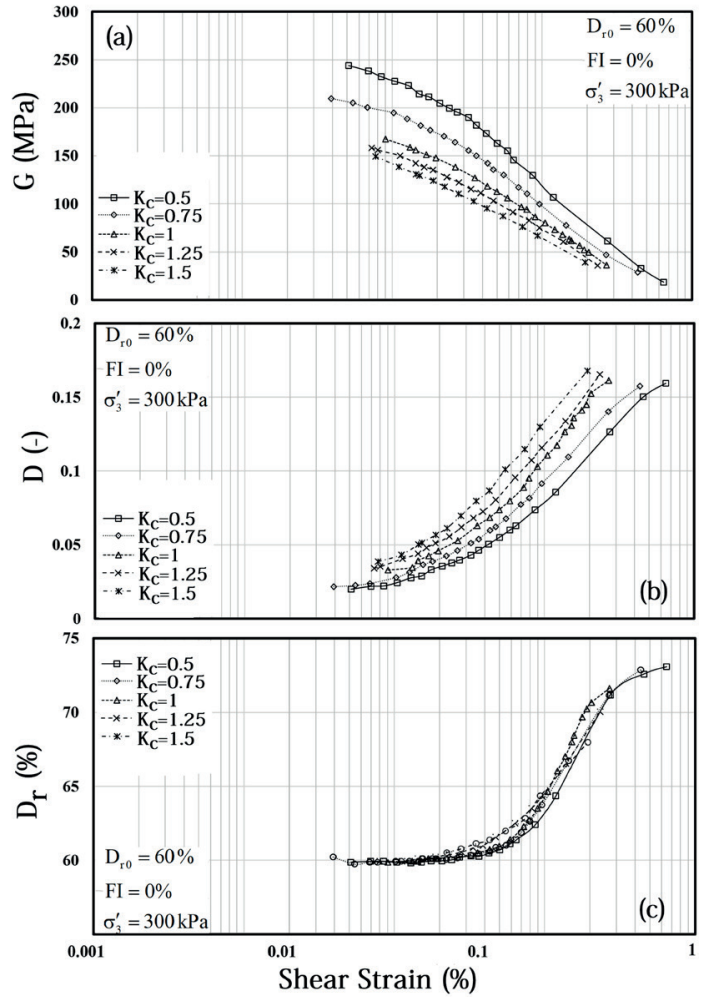

Fig. 13 ((a) Variation of $G$; (b) Variation of $D$; (C) variation of $D_{r}$ as a function of $\gamma$ in terms of $\mathrm{KC}\left(D_{r 0}=60 \%,=300 \mathrm{kPa}\right.$ and $\left.F I=0 \%\right)$
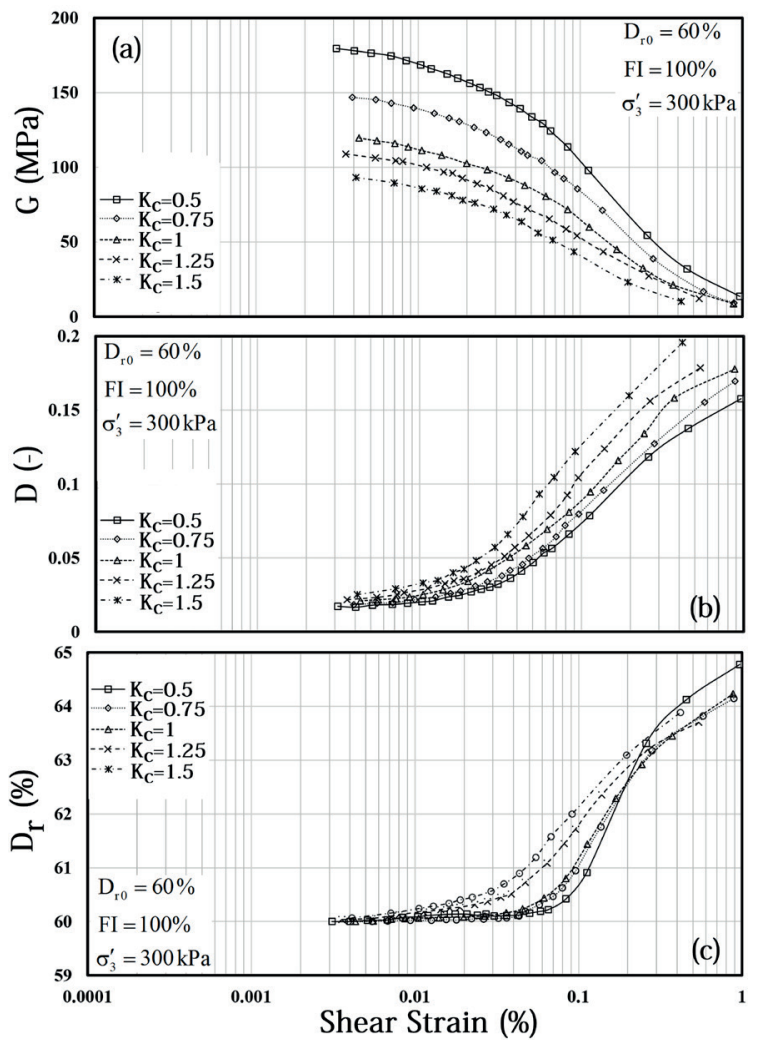

Fig. 14 (a) Variation of v; (b) Variation of $D$; (C) variation of $D_{r}$ as a function of $\gamma$ in terms of $\mathrm{KC}\left(D_{r 0}=60 \%,=300 \mathrm{kPa}\right.$ and $\left.F I=100 \%\right)$ 
As shown in the results, an increase in $K_{C}$ decreased shear modulus and increased damping ratio which may be because of a decrease in the mean effective stress $\left(\sigma_{m}^{\prime}=\left(2 \sigma_{h}^{\prime}+\sigma_{v}^{\prime}\right) / 3\right)$. This finding is in good agreement with the results of Sun et al. [59], which demonstrated an increase in normalized shear modulus due to an increase of the initial shear stress.

The results also confirm that the effect of $K_{C}$ on the volume change is negligible for gravel, whereas this effect is more impressive for fouling sand. The effect of $K_{C}$ on relative density change of fouling sand is a function of the shear strain level so that an increase in $K_{C}$ may lead to an increase or decrease in relative density depending on shear strain level.

\section{Conclusions}

In the present study, an experimental study was performed to investigate of dynamic properties and volume change of both clean and fouled gravel specimens. Based on the results, the following conclusions can be drawn:

The fouled gravel specimen with $50 \%$ sand has higher shear modulus than others at shear strain lower than $0.01 \%$; however, these specimens exhibit the largest damping ratio or volume reduction at shear strain greater than $0.1 \%$. The

\section{References}

[1] Karg, C. "Modelling of strain accumulation due to low level vibrations in granular soils", Doctoral dissertation, Ghent University, 2008. [online] Available at: https://lib.ugent.be/catalog/pug01:481429

[2] Wu, Y., Yamamoto, H., Cui, J., Cheng, H. "Influence of Load Mode on Particle Crushing Characteristics of Silica Sand at High Stresses", International Journal of Geomechanics, 20(3), pp. 1-14, 2020. https://doi.org/10.1061/(ASCE)GM.1943-5622.0001600

[3] Donohue, S., O'Sullivan, C., Long, M. "Particle breakage during cyclic triaxial loading of a carbonate sand", Géotechnique, 59(5), pp. 477-482, 2009. https://doi.org/10.1680/geot.2008.T.003

[4] Hyodo, M., Wu, Y., Aramaki, N., Nakata, Y. "Undrained monotonic and cyclic shear response and particle crushing of silica sand at low and high pressures", Canadian Geotechnical Journal, 54(2), pp. 207-218, 2017. https://doi.org/10.1139/cgj-2016-0212

[5] Chen, X., Zhang, J. "Influence of Relative Density on Dilatancy of Clayey Sand-Fouled Aggregates in Large-Scale Triaxial Tests", Journal of Geotechnical and Geoenvironmental Engineering, 142(10), 2016

https://doi.org/10.1061/(ASCE)GT.1943-5606.0001542

[6] Qian, Y., Mishra, D., Tutumluer, E., Kazmee, H. A. "Characterization of geogrid reinforced ballast behavior at different levels of degradation through triaxial shear strength test and discrete element modeling", Geotextiles and Geomembranes, 43(5), pp. 393-402, 2015. https://doi.org/10.1016/j.geotexmem.2015.04.012 effect of FI on the shear modulus is reduced at large shear strain levels. Also, the results show that shear strain level has considerable effect on the dynamic properties and volume change, increasing the shear strain level results in decreasing and increasing the stiffness and damping ratio or relative density, respectively. Stiffness and volumetric contraction of all specimens increased as the mean effective confining pressure increased from $100 \mathrm{kPa}$ to $600 \mathrm{kPa}$. The effect of mean effective confining pressure on the volumetric contraction is more pronounced for large shear strains and less pronounced for the small and medium shear strain levels. The results of anisotropic consolidation tests on both clean gravel and sand indicate that an increase in $K_{C}$ decreased shear modulus and this decrease is more pronounced at small and medium than at large shear strain. In other words, the shear modulus of both clean gravel and sand under anisotropic compression mode $\left(K_{C}<1\right)$ are larger than those in extension $\left(K_{C}>1\right)$ or isotropic mode $\left(K_{C}=1\right)$. However, an increase in $\mathrm{KC}$ increased damping ratio of both clean gravel and sand especially at shear strain greater than $0.1 \%$. The results also confirm that the effect of anisotropic consolidation on the volume change of the specimens is a function of the shear strain level and is negligible for clean gravel, whereas this effect is more impressive for sand.

[7] Guoxing, C., Qi, W., Tian, S., Kai, Z., Enquan, Z., Lingyu, X. Yanguo, Z. "Cyclic Behaviors of Saturated Sand-Gravel Mixtures under Undrained Cyclic Triaxial Loading", Journal of Earthquake Engineering, 2018 https://doi.org/10.1080/13632469.2018.1540370

[8] Cabalar, A. F., Hasan, R. A. "Compressional behaviour of various size/shape sand-clay mixtures with different pore fluids", Engineering Geology, 164, pp. 36-49, 2013. https://doi.org/10.1016/j.enggeo.2013.06.011

[9] Cabalar, A. F., Mustafa, W. S. "Fall cone tests on clay-sand mixtures", Engineering Geology, 192, pp. 154-165, 2015. https://doi.org/10.1016/j.enggeo.2015.04.009

[10] Xiao, Y., Liu, H., Desai, C. S., Sun, Y., Liu, H. "Effect of Intermediate Principal-Stress Ratio on Particle Breakage of Rockfill Material", Journal of Geotechnical and Geoenvironmental Engineering, 142(4), 2016 https://doi.org/10.1061/(ASCE)GT.1943-5606.0001433

[11] Xiao, Y., Liu, H., Chen, Y., Jiang, J. "Strength and deformation of rockfill material based on large-scale triaxial compression tests. II: Influence of particle breakage", Journal of Geotechnical and Geoenvironmental Engineering, 140(12), 2014 https://doi.org/10.1061/(ASCE)GT.1943-5606.0001177

[12] Xiao, Y., Liu, H., Chen, Y., Zhang, W. "Particle size effects in granular soils under true triaxial conditions", Géotechnique, 64(8), pp. 667-672, 2014. https://doi.org/10.1680/geot.14.T.002 
[13] Indraratna, B., Khabbaz, M. H., Lackenby, J. "Behaviour of railway ballast under dynamic loads based on large-scale triaxial testing", In: AusRAIL PLUS 2003, Sydney, NSW, Australia, 2003, pp. 17-19.

[14] Selig, E. T., Waters, J. M. "Track geotechnology and substructure management", Thomas Telford, London, UK, 1994. https://doi.org/10.1680/tgasm.20139

[15] Huang, H., Tutumluer, E., Dombrow, W. "Laboratory Characterization of Fouled Railroad Ballast Behavior", Transportation Research Record: Journal of the Transportation Research Board, 2117(1), pp. 93-101, 2009. https://doi.org/10.3141/2117-12

[16] Danesh, A., Palassi, M., Mirghasemi, A. A. "Effect of sand and clay fouling on the shear strength of railway ballast for different ballast gradations", Granular Matter, 20, Article number: 51, 2018. https://doi.org/10.1007/s10035-018-0824-z

[17] Danesh, A., Palassi, M., Mirghasemi, A. A. "Evaluating the influence of ballast degradation on its shear behaviour", International Journal of Rail Transportation, 6(3), pp. 145-162, 2018. https://doi.org/10.1080/23248378.2017.1411212

[18] Qian, Y., Tutumluer, E., Hashash, Y. M. A., Ghaboussi, J. "Effects of Ballast Degradation on Permanent Deformation Behavior From Large-Scale Triaxial Tests", presented at Proceedings of the 2014 Joint Rail Conference, Colorado Springs, CO, USA, April, 2-4, 2014, Paper number: JRC2014-3806 https://doi.org/10.1115/JRC2014-3806

[19] Thakur, P. K., Vinod, J. S., Indraratna, B. "Effect of confining pressure and frequency on the deformation of ballast", Géotechnique, 63(9), pp. 786-790, 2013. https://doi.org/10.1680/geot.12.T.001

[20] Gupta, A. K. "Effects of particle size and confining pressure on breakage factor of rockfill materials using medium triaxial test", Journal of Rock Mechanics and Geotechnical Engineering, 8(3), pp. 378-388, 2016. https://doi.org/10.1016/j.jrmge.2015.12.005

[21] Jia, Y., Xu, B., Chi, S., Xiang, B., Zhou, Y. "Research on the Particle Breakage of Rockfill Materials during Triaxial Tests", International Journal of Geomechanics, 17(10), 2017. https://doi.org/10.1061/(ASCE)GM.1943-5622.0000977

[22] Xiao, Y., Liu, H., Chen, Q., Ma, Q., Xiang, Y., Zheng, Y. "Particle breakage and deformation of carbonate sands with wide range of densities during compression loading process", Acta Geotechnica, 12, pp. 1177-1184, 2017. https://doi.org/10.1007/s11440-017-0580-y

[23] Xiao, Y., Liu, H., Chen, Q., Long, L., Xiang, J. "Evolution of particle breakage and volumetric deformation of binary granular soils under impact load", Granular Matter, 19, Article number: 71, 2017. https://doi.org/10.1007/s10035-017-0756-Z

[24] Xiao, Y., Liu, H., Ding, X., Chen, Y., Jiang, J., Zhang, W. "Influence of Particle Breakage on Critical State Line of Rockfill Material", International Journal of Geomechanics, 16(1), 2016. https://doi.org/10.1061/(ASCE)GM.1943-5622.0000538

[25] Yu, F. W. "Particle breakage and the critical state of sands", Géotechnique, 67(8), pp. 713-719, 2017. https://doi.org/10.1680/jgeot.15.P.250
[26] McDowell, G. R., Li, H. "Discrete element modelling of scaled railway ballast under triaxial conditions", Granular Matter, 18, Article number: 66, 2016.

https://doi.org/10.1007/s10035-016-0663-8

[27] Sun, Y., Nimbalkar, S., Chen, C. "Particle breakage of granular materials during sample preparation", Journal of Rock Mechanics and Geotechnical Engineering, 11(2), pp. 417-422, 2019. https://doi.org/10.1016/j.jrmge.2018.12.001

[28] Indraratna, B., Thakur, P. K., Vinod, J. S., Salim, W. "Semiempirical Cyclic Densification Model for Ballast Incorporating Particle Breakage", International Journal of Geomechanics, 12(3), pp. 260271, 2012.

https://doi.org/10.1061/(ASCE)GM.1943-5622.0000135

[29] Kong, X., Liu, J., Zou, D., Liu, H. "Stress-Dilatancy Relationship of Zipingpu Gravel under Cyclic Loading in Triaxial Stress States", International Journal of Geomechanics, 16(4), 2016. https://doi.org/10.1061/(ASCE)GM.1943-5622.0000584

[30] Indraratna, B., Thakur, P. K., Vinod, J. S. "Experimental and Numerical Study of Railway Ballast Behavior under Cyclic Loading", International Journal of Geomechanics, 10(4), pp. 136144, 2010. https://doi.org/10.1061/(ASCE)GM.1943-5622.0000055

[31] Zhang, B. Y., Zhang, J. H., Sun, G. L. "Deformation and shear strength of rockfill materials composed of soft siltstones subjected to stress, cyclical drying/wetting and temperature variations", Engineering Geology, 190, pp. 87-97, 2015. https://doi.org/10.1016/j.enggeo.2015.03.006

[32] Khonji, A., Bagherzadeh-Khalkhali, A., Aghaei-Araei, A. "Experimental investigation of rockfill particle breakage under largescale triaxial tests using five different breakage factors", Powder Technology, 363, pp. 473-487, 2020. https://doi.org/10.1016/j.powtec.2020.01.032

[33] Yu, F. "Characteristics of particle breakage of sand in triaxial shear", Powder Technology, 320, pp. 656-667, 2017. https://doi.org/10.1016/j.powtec.2017.08.001

[34] Lenart, S., Koseki, J., Miyashita, Y., Sato, T. "Large-scale triaxial tests of dense gravel material at low confining pressures", Soils and Foundations, 54(1), pp. 45-55, 2014. https://doi.org/10.1016/j.sandf.2013.12.005

[35] Goudarzy, M., König, D., Schanz, T. "Small strain stiffness of granular materials containing fines", Soils and Foundations, 56(5), pp. 756-764, 2016. https://doi.org/10.1016/j.sandf.2016.08.002

[36] Bayat, E., Bayat, M. "Effect of grading characteristics on the undrained shear strength of sand: review with new evidences", Arabian Journal of Geosciences, 6, pp. 4409-4418, 2013. https://doi.org/10.1007/s12517-012-0670-y

[37] Cabalar, A. F. "Applications of the oedometer, triaxial and resonant column tests to the study of micaceous sands", Engineering Geology, 112(1-4), pp. 21-28, 2010. https://doi.org/10.1016/j.enggeo.2010.01.004

[38] Maleki, M., Ezzatkhah, A., Bayat, M., Mousivand, M. "Effect of physical parameters on static undrained resistance of sandy soil with low silt content", Soil Dynamics and Earthquake Engineering, 31(10), pp. 1324-1331, 2011. https://doi.org/10.1016/j.soildyn.2011.05.003 
[39] Yu, X., Sun, R., Yuan, X., Chen, Z., Zhang, J. "Resonant Column Test on the Frozen Silt Soil Modulus and Damping at Different Temperatures", Periodica Polytechnica Civil Engineering, 61(4), pp. 762-769, 2017. https://doi.org/10.3311/PPci.10349

[40] Wang, Y., Benahmed, N., Cui, Y.-J., Tang, A. M. "A novel method for determining the small-strain shear modulus of soil using the bender elements technique", Canadian Geotechnical Journal, 54(2), pp. 280-289, 2017. https://doi.org/10.1139/cgj-2016-0341

[41] Li, W., Lang, L., Wang, D., Wu, Y., Li, F. "Investigation on the dynamic shear modulus and damping ratio of steel slag sand mixtures", Construction and Building Materials, 162, pp. 170-180, 2018. https://doi.org/10.1016/j.conbuildmat.2017.12.026

[42] Youn, J.-U., Choo, Y.-W., Kim, D.-S. "Measurement of small-strain shear modulus Gmax of dry and saturated sands by bender element, resonant column, and torsional shear tests", Canadian Geotechnical Journal, 45(10), pp. 1426-1438, 2008. https://doi.org/10.1139/T08-069

[43] Xiao, H., Yao, K., Liu, Y., Goh, S.-H., Lee, F.-H. "Bender element measurement of small strain shear modulus of cement-treated marine clay - Effect of test setup and methodology", Construction and Building Materials, 172, pp. 433-447, 2018.

[44] Mital, U., Kawamoto, R., Andrade, J. E. "Effect of fabric on shear wave velocity in granular soils", Acta Geotechnica, 15, pp. 11891203, 2020.

https://doi.org/10.1007/s11440-019-00766-1

[45] Edincliler, A., Cabalar, A. F., Cevik, A., Isik, H. "New Formulations for Dynamic Behavior of Sand-Waste Tire Mixtures in a Small Range of Strain Amplitudes", Periodica Polytechnica Civil Engineering, 62(1), pp. 92-101, 2018. https://doi.org/10.3311/PPci.8698

[46] Rahman, M. E., Pakrashi, V., Banerjee, S., Orr, T. "Suitable Waves for Bender Element Tests: Interpretations, Errors and Modelling Aspects", Periodica Polytechnica Civil Engineering, 60(2), pp. 145$158,2016$. https://doi.org/10.3311/PPci.7952

[47] Senetakis, K., Payan, M. "Small strain damping ratio of sands and silty sands subjected to flexural and torsional resonant column excitation", Soil Dynamics and Earthquake Engineering, 114, pp. 448459, 2018.

https://doi.org/10.1016/j.soildyn.2018.06.010

[48] Moayerian, S. "Effect of Loading Frequency on Dynamic Properties of Soils Using Resonant Column", MAS Thesis, University of Waterloo, 2012. [online] Available at: http://hdl.handle.net/ $10012 / 6563$
[49] Subramaniam, P., Banerjee, S. "Torsional Shear and Resonant Column Tests on Cement Treated Marine Clay", Indian Geotechnical Journal, 46, pp. 183-191, 2016. https://doi.org/10.1007/s40098-015-0170-6

[50] Frost, J. D., Park, J. Y. "A critical Assessment of the Moist Tamping Technique", Geotechnical Testing Journal, 26(1), pp. 57-70, 2003. https://doi.org/10.1520/gtj11108j

[51] Maleki, M., Bayat, M. "Experimental evaluation of mechanical behavior of unsaturated silty sand under constant water content condition", Engineering Geology, 141-142, pp. 45-56, 2012. https://doi.org/10.1016/j.enggeo.2012.04.014

[52] Rahman, M. M., Lo, S. R. "Discussion of the paper: Effect of physical parameters on static undrained resistance of sandy soil with low fines content", Soil Dynamics and Earthquake Engineering, 52, pp. 138-140, 2013. https://doi.org/10.1016/j.soildyn.2012.09.009

[53] Ladd, R. S. "Specimen Preparation and Cyclic Stability of Sands", Journal of the Geotechnical Engineering Division, 103(6), pp. 535$547,1977$.

[54] Karim, M. E.,Alam, M. J. "Undrained monotonic and cyclic response of sand-silt mixtures", International Journal of Geotechnical Engineering, 10(3), pp. 223-235, 2016. https://doi.org/10.1179/1939787915Y.0000000023

[55] Skempton, A. W. "The Pore-Pressure Coefficients A and B", Géotechnique, 4(4), pp. 143-147, 1954. https://doi.org/10.1680/geot.1954.4.4.143

[56] Lade, P. V., Yamamuro, J. A. "Effects of nonplastic fines on static liquefaction of sands", Canadian Geotechnical Journal, 34(6), pp. 918-928, 1997. https://doi.org/10.1139/t97-052

[57] Cherian, A. C., Kumar, J. "Effects of Vibration Cycles on Shear Modulus and Damping of Sand Using Resonant Column Tests", Journal of Geotechnical and Geoenvironmental Engineering, 142(12), 2016 https://doi.org/10.1061/(ASCE)GT.1943-5606.0001545

[58] Maheshwari, B. K., Kale, S. S., Kaynia, A. M. "Dynamic properties of Solani sand at large strains: A parametric study", International Journal of Geotechnical Engineering, 6(3), pp. 353-358, 2012. https://doi.org/10.3328/IJGE.2012.06.03.353-358

[59] Sun, J., Gong, M., Tao, X. "Dynamic shear modulus of undisturbed soil under different consolidation ratios and its effects on surface ground motion", Earthquake Engineering and Engineering Vibration, 12, pp. 561-568, 2013. https://doi.org/10.1007/s11803-013-0197-6 